\title{
RAPID PROBABILISTIC HURRICANE SURGE AND DAMAGE FORECASTING USING SURGE RESPONSE FUNCTIONS
}

\author{
Jennifer L. Irish ${ }^{1}$, Celso Ferreira ${ }^{2}$, Francisco Olivera ${ }^{2}$, Ikpoto Udoh ${ }^{1}$, \\ Youn Kyung Song ${ }^{1}$, and Kuang-An Chang ${ }^{1}$
}

\begin{abstract}
In this paper, a joint probability approach is used with scaling laws for hurricane surge to rapidly develop probabilistic based hurricane surge and damage forecasts. The method presented is demonstrated along the Texas, USA coastline for Hurricane Ike, which made landfall in September of 2008. The probabilistic approach presented here is both accurate and fast, with a single surge and percent damage forecast taking less than one minute while representing more than 170,000 distinct hurricane possibilities.
\end{abstract}

Keywords: hurricane surge; surge forecasting; flooding damages

\section{INTRODUCTION}

Recent hurricanes seasons, which included Hurricanes Katrina, Rita, and Ike, resulted in some of the largest surges on record in the United States. Yet, our ability to rapidly and accurately convey surge hazard to the public and to policymakers in an easy-to-interpret format has left many in harms way. To fully convey surge hazard requires both a reliable estimate of surge elevation and a measure of expected damages (Irish and Resio 2010). Significant advances in physics-based surge modeling over the last several decades now make it possible to accurately simulate hurricane surge at high resolution (e.g., Westerink et al. 2008, Mattocks and Forbes 2008). However, real-time simulation with high-resolution numerical models is limited by computational requirements, and, when these models are employed in a forecast mode, the number of storm possibilities considered, namely track and intensity combinations, is severely limited.

Here, we present a method that uses scaling laws and joint probability statistics to make nearinstantaneous probabilistic surge predictions, where the scaling laws are derived from the governing equations for surge generation and high-resolution numerical simulations with ADCIRC (Luettich and Westerink 2004). By additionally coupling these surge projections with damage estimates, we then present a means for projecting surge-related economic damages. In a geographic information framework, predetermined damages per $10-\mathrm{km}$ of coastline are tabulated for automatic query based on the abovementioned probabilistic surge forecasts. Final surge and damage forecasts include a probabilistic surge forecast and an estimate of the spatial distribution of economic damages for the region of interest.

\section{STUDY AREA}

The study area extends approximately $300 \mathrm{~km}$ of coastline along the northern United States Gulf of Mexico, spanning from Matagorda, Texas to the Texas/Louisiana border (Figure 1). Several populated communities line the Texas coast, including the city of Galveston. Texas supports an array of industries, including oil and gas and tourism. This region is also prone to hurricane activity, and much of the coastal area is low-lying, making the region susceptible to coastal flooding. Over the last half decade, this region has been impacted by surges generated by Hurricanes Katrina, Rita, Dolly, and most recently by Ike.

On September 13, 2008, Hurricane Ike made landfall in Galveston (Berg 2009). At landfall, this Category 2 hurricane had a central pressure of $950 \mathrm{mb}$ and a radius to hurricane force winds of $195 \mathrm{~km}$. Hurricane Ike generated high surges along the northeastern half of the Texas coast, and surrounding areas. Highest flood elevations were observed on Bolivar Island, to the northeast of Galveston.

\section{METHODS}

\section{Surge Prediction with Surge Response Functions (SRF)}

Peak hurricane surge at some location $x, \zeta(x)$, is a function of hurricane meteorological conditions as well as regional and local topographic conditions. Thus, surge can be written as:

\footnotetext{
${ }^{1}$ Coastal and Ocean Engineering Division, Zachry Department of Civil Engineering, Texas A\&M University, College Station, TX, 77843-3136, USA

2 Environmental and Water Resources Division, Zachry Department of Civil Engineering, Texas A\&M University, College Station, TX, 77843-3136, USA
} 


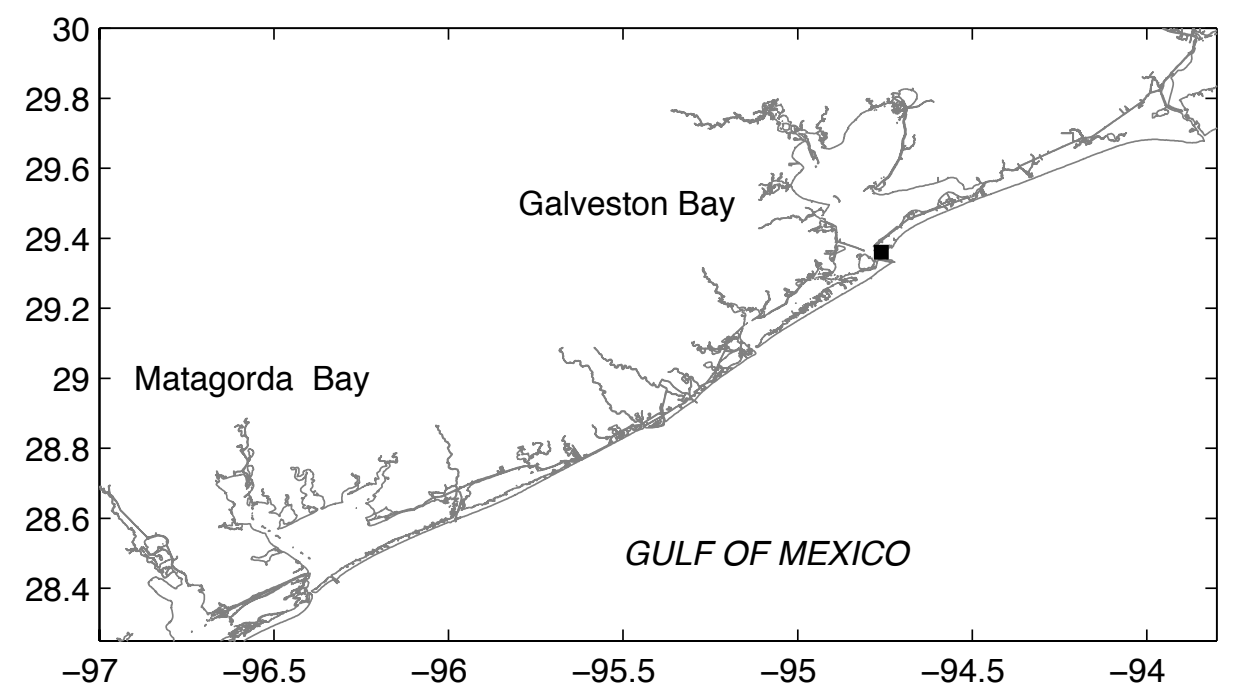

Figure 1. Map of study area: State of Texas, USA. Square indicates observed landfall position of Hurricane Ike (2008).

$$
\zeta(x)=\Phi\left(x_{o}, c_{p}, R_{\max }, v_{f}, \theta_{l}, x\right)
$$

where:

$\Phi$ is a dimensional surge response function (SRF),

$x_{o}$ is hurricane landfall location,

$c_{p}$ is central pressure,

$R_{\max }$ is radius to maximum wind (a measure of size),

$v_{f}$ is forward speed, and

$\theta_{l}$ is track angle with respect to coastline orientation.

In Irish et al. (2009), the following dimensionless SRF form was introduced, where the influence of forward speed and track angle were assumed small, with respect to other parameters:

$$
\begin{gathered}
\zeta^{\prime}=\frac{\rho g \zeta}{\left(P_{f a r}-c_{p}\right)}+m_{x}\left(P_{f a r}-c_{p}\right) \\
x^{\prime}=\left(\frac{\left[x-x_{o}\right]}{\alpha R_{\max }}-\lambda\right)-F\left(1-\frac{R_{\max }}{R_{\text {thres }}}\right)
\end{gathered}
$$

where:

$x^{\prime}$ is a dimensionless alongshore function,

$\alpha$ is a parameter to scale $R_{\max }$,

$\lambda$ is a regional constant (Song 2009)

$F$ is a location-dependent fitting kernel, and

$R_{\text {thres }}$ is a constant, reference hurricane size threshold.

A complete discussion of Equation 2 can be found in Irish et al. (2009). SRFs were developed for the Texas coast using the hydrodynamic model ADCIRC (Luettich and Westerink 2004) and a discrete set of hurricane conditions, which spanned the range of central pressures, radii to maximum wind, and 
landfall locations expected in the Gulf of Mexico. While certainly important for coastal flooding, wave setup was not included here in the development of the SRFs. Irish et al. (in review) show that the SRFgenerated surges compare well to water level and high water mark observations for historical hurricanes impacting the Texas coast, with respect to both magnitude and distribution along the coast.

\section{Damage Estimation}

Potential economic damages were assessed from within a geographic information system, following the methods presented in Frey et al. (in press). Several simplifying assumptions were employed:

1. Economic damages were based on damage relationships within the Federal Emergency Management Agency's (FEMA) HAZUS database (FEMA 2009).

2. Damage to residential, commercial, industrial, public, and agricultural structures were based on information contained in the HAZUS General Building Stock Database (FEMA 2009).

3. Inundated area was determined by intersecting the predicted surge with U.S. Geological Survey 10-m topography.

4. Only damages extending $1.6 \mathrm{~km}$ inland from the open coast were considered, such that damages in coastal regions along estuaries and bays were ignored.

The Texas coastline was segmented into $10-\mathrm{km}$ segments, and then damages were tabulated for each segment based on surge elevations above mean sea level of 1.5, 3.0, 4.6, 6.1, and 7.6 m.

\section{Probability Specification}

Probabilistic surge and damage estimates were made by assuming a joint probability distribution, $p$ (probability of exceedance), in the following form:

$$
p=p\left(c_{p}\right) \cdot p\left(R_{\max }\right) \cdot p\left(x_{o}\right)
$$

where:

$p\left(c_{p}\right)$ is probability the hurricane will have intensity $c_{p}$ at landfall,

$p\left(R_{\max }\right)$ is probability the hurricane will have storm size $R_{\max }$ at landfall, and

$p\left(x_{o}\right)$ is probability the hurricane will make landfall at location $x_{o}$.

The probabilities $p\left(c_{p}\right), p\left(R_{\max }\right)$, and $p\left(x_{o}\right)$ were specified based on publicly available hurricane observations and forecasts posted by the National Hurricane Center (2009). A complete discussion of the probabilistic forecast methodology can be found in Irish et al. (in review).

\section{RESULTS}

Hurricane surge and percent damage forecasts were generated from the National Hurricane Center's meteorological forecasts made 72, 48, 24, and 12 hours prior to landfall. Each probabilistic forecast considers 171,360 different combinations of central pressure, radius to maximum wind, and landfall position. The probabilistic forecast for surge and damages was completed in about 30 seconds in Fortran on a $3.2 \mathrm{GHz}$ Xeon processor. Figure 2 shows the probabilistic surge projection for Hurricane Ike at 12 hours prior to landfall. This figure shows that high surges are projected to occur in the vicinity of Galveston, with highest surges to be slightly northeast, on Bolivar peninsula. This forecast aligns well with actual observed surges during Hurricane Ike (Berg 2009), as shown in Irish et al. (in review). The SRF prediction using actual observed meteorological statistics at landfall gives surges within $p=0.50$ and 0.75 for all locations presented; the difference in surge levels between these two probability intervals is $1 \mathrm{~m}$ or less. A complete discussion of the probabilistic surge forecasts for Hurricane Ike can be found in Irish et al. (in review).

Figure 3 shows the probabilistic percent damage projection for Hurricane Ike at 12 hours prior to landfall. Percent damage here is defined as the damaged value within the $10 \mathrm{~km}$ segment divided by the total value for the entire stretch of coast from Matagorda Bay, Texas to the Texas/Louisiana border, multiplied by $100 \%$. Coastal development along the Texas coastline is concentrated in the Galveston area, thus the highest percentage of development is concentrated in Galveston. The high surges forecasted for Galveston Island along with the potential for damages result in highest forecasted damages on Galveston Island, in the area to the east of observed landfall and highest surges. Significant 


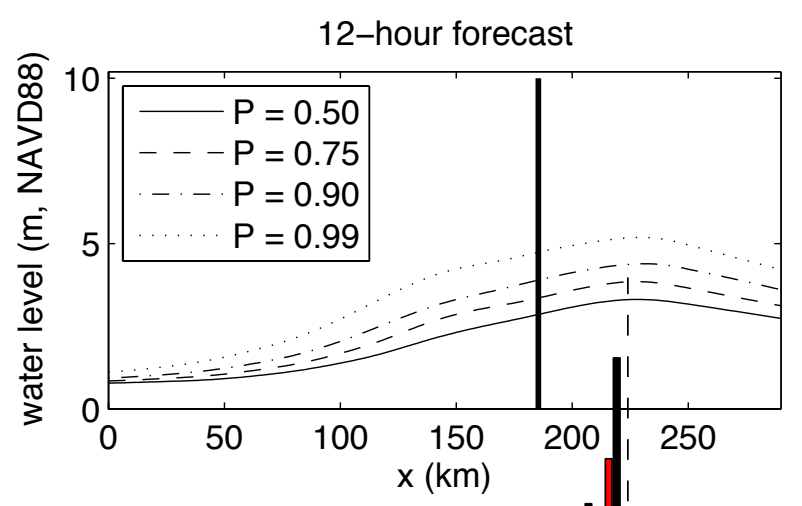

Figure 2. Surge forecast for Hurricane lke (2008) at 12 hours from landfall. Horizontal axis is alongshore position, measured from the southwestern end of Matagorda Bay (see Figure 1). Vertical line indicates actual landfall position of Hurricane Ike in Galveston, Texas (modified from Irish et al. in review).

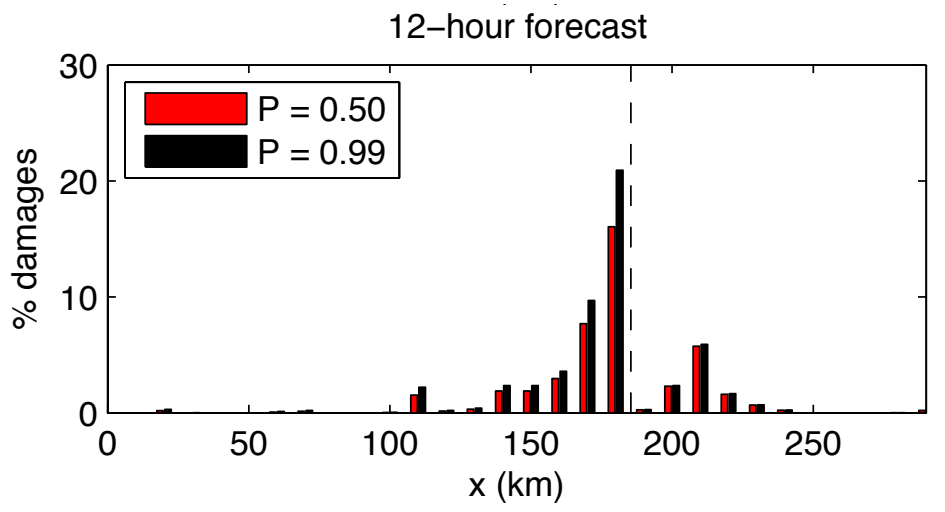

Figure 3. Damage forecast for Hurricane Ike (2008) at 12 hours from landfall. Horizontal axis is alongshore position, measured from the southwestern end of Matagorda Bay (see Figure 1). Percent damages represents percent of entire value for the stretch of coast from Matagorda Bay, Texas to the Texas/Louisiana border. Vertical dashed line indicates actual landfall position of Hurricane Ike in Galveston, Texas.

damages are also projected for Bolivar peninsula, the area where highest surges are projected. However, due to the relatively lower percent of infrastructure and development value on the Bolivar peninsula, with respect to Galveston Island, the percent damage forecast is relatively lower. Percent damages to the south, where surges were lowest, and to the northeast, where percent of development is low, are projected to experience low amounts of damage.

\section{CONCLUSIONS}

The proposed probabilistic surge methodology is both fast and accurate, as shown for Hurricane Ike in 2008 along the Texas coast, from Matagorda to the Texas-Louisiana border (Irish et al. in review). The forecasts developed for hurricane surge and percent damages each required about 30 seconds of computation time (in Fortran on a 3.2-GHz Xeon processor) and explicitly represent surge estimates and damage calculations for more than 170,000 individual hurricane track, storm intensity, and landfall location sets that span the hurricane meteorological parameter space. The proposed method provides a framework for fast and accurate probabilistic assessment of hurricane risk that can be used to inform evacuation planning, emergency response, and post-storm recovery efforts.

\section{ACKNOWLEDGMENTS}

This research was supported by the Office of Science (BER) U.S. Department of Energy (Grant No. DE-FG02-08ER64644) and by the Texas General Land Office, via Grant/Cooperative Agreement from the National Oceanic and Atmospheric Administration (Grant No. C10-00179). The views expressed herein are those of the authors and do not necessarily reflect views of NOAA or any of its 
subagencies. The authors wish to thank Oceanweather, Inc., for allowing use of their Planetary Boundary Layer model, and Dr. Andrew Kennedy, for allowing use of his water level filtering routines.

\section{REFERENCES}

Berg, R. 2009. Tropical cyclone report Hurricane Ike (AL092008) 1-14 September 2008, National Hurricane Center, 55 pp.

Federal Emergency Management Agency. 2009. HAZUS FEMA's Methodology for Estimating Potential Losses from Disasters, http://www.fema.gov/plan/prevent/hazus.

Frey, A.E., Olivera, F., Irish, J.L., Dunkin, L.M., Kaihatu, J.M., Ferreira, C.M., and Edge, B.L. The impact of climate change on hurricane flooding inundation, population affected, and property damages, Journal of the American Water Resources Association.

Irish, J.L., and Resio, D.T. 2010. A hydrodynamics-based surge scale for hurricanes, Ocean Engineering, 37(11-12), 1085-1088.

Irish, J.L., Resio, D.T., and Cialone, M.C. 2009. A surge response function approach to coastal hazard assessment. Part 2: Quantification of spatial attributes of response functions, Natural Hazards, 51(1), 183-205.

Irish, J.L., Song, Y.K., and Chang, K.-A. In review. Probabilistic hurricane surge forecasting using parameterized surge response functions, Geophysical Research Letters.

Luettich, R.A., and Westerink, J.J. 2004. Formulation and numerical implementation of the 2D/3D ADCIRC finite element model version 44.XX, http://www.adcirc.org.

Mattocks, C., Forbes, C. 2008. A real-time event-triggered storm surge forecasting system for the state of North Carolina, Ocean Modelling, 25(3-4), 95-119.

National Hurricane Center. 2009. NHC archive of hurricane seasons, http://www.nhc.noaa.gov/pastall.shtml.

Song, Y.K. 2009. Storm surge assessment at Texas coastal bridges with improved surge response functions, Master Thesis, Texas A\&M University, College Station, Texas, $110 \mathrm{pp}$.

Westerink, J.J., Luettich, R.A., Feyen, J.C., Atkinson, J.H., Dawson, C., Powell, M.D., Dunion, J.P., Roberts, H.J., and Pourtaheri, H. 2008. A basin to channel scale unstructured grid hurricane storm surge model as implemented for Southern Louisiana, Monthly Weather Review, 136, 833-865. 